\title{
Producing Fractional Rangeland Component Predictions in a Sagebrush Ecosystem, a Wyoming Sensitivity Analysis
}

Open-File Report 2012-1239 



\section{Producing Fractional Rangeland Component Predictions in a Sagebrush Ecosystem, a Wyoming Sensitivity Analysis}

By George Xian, Collin Homer, Brian Granneman, and Debbie Meyer

Open-File Report 2012-1239 


\section{U.S. Department of the Interior \\ KEN SALAZAR, Secretary \\ U.S. Geological Survey \\ Marcia K. McNutt, Director}

\section{U.S. Geological Survey, Reston, Virginia: 2012}

For more information on the USGS - the Federal source for science about the Earth, its natural and living resources, natural hazards, and the environment, visit http://www.usgs.gov or call 1-888-ASK-USGS.

For an overview of USGS information products, including maps, imagery, and publications, visit http://www.usgs.gov/pubprod

To order other USGS information products, visit http://store.usgs.gov

Any use of trade, firm, or product names is for descriptive purposes only and does not imply endorsement by the U.S. Government.

Although this information product, for the most part, is in the public domain, it also may contain copyrighted materials as noted in the text. Permission to reproduce copyrighted items must be secured from the copyright owner.

Suggested citation:

Xian, George, Homer, Collin, Granneman, Brian, and Meyer, Debbie, 2012, Producing fractional rangeland component predictions in a sagebrush ecosystem, a Wyoming sensitivity analysis: U.S. Geological Survey Open-File Report 2012-1239, $18 p$ 


\section{Contents}

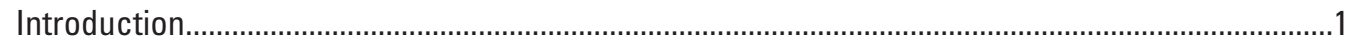

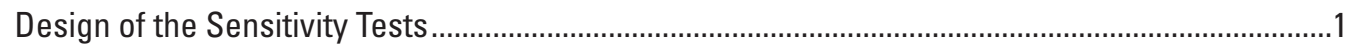

Background on Component Measurement Methods ................................................................

QuickBird Scene Training Sensitivity ................................................................................ 2

QuickBird Field Training Sample Size Sensitivity ................................................................

Landsat Mosaic Evaluation ..............................................................................................

Landsat Mosaic Evaluation Across Different Ecological Zones.............................................4

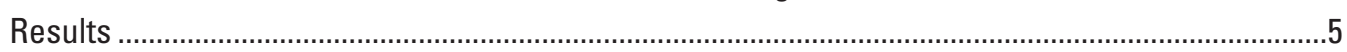

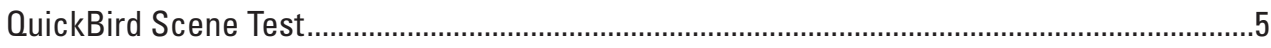

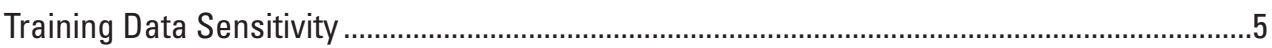

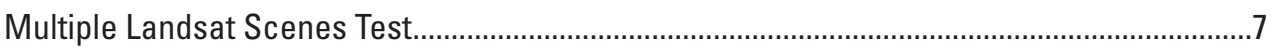

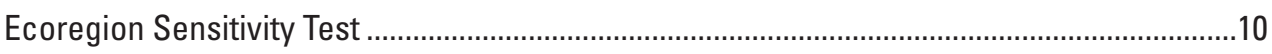

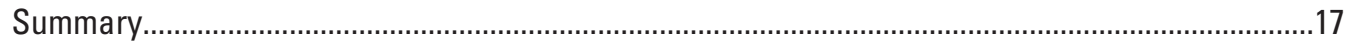

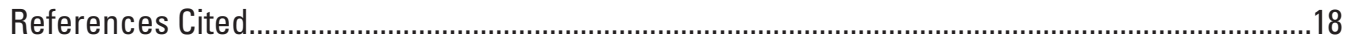

\section{Figures}

1. Map showing the extent of Landsat $p 37 / r 31$ and locations of QuickBird images

2. Map showing the spatial extent of sensitivity tests with 2 (p37/r31 and $\mathrm{p} 37 / \mathrm{r} 30)$

(MT-2 test); 3 (p37/r31, p37/r30, and p36/r31) (MT-3 test); 4 (p37/r31, p37/r30, p36/r31, and p36/r30) (MT-4 test); and 6 (p37/r31, p37/r30, P36/R31, p36/r30, p35/r31, and p36/r29) (MT-6 test) Landsat scenes mosaic

3. Map showing the Landsat scenes used for different ecological zone tests......................6

4. Mosaic showing percent covers of sagebrush components obtained using different numbers of QuickBird imagery.

5. Graphs showing field sample sensitivity test for three Landsat footprints. Root mean square error and square of correlation coefficient are calculated using re-estimate and 2006 products

6. Graphs showing average root mean square error (a) and (b) by comparing reference and re-estimate datasets for three Landsat path/rows.

7. Mosaic showing percent covers of sagebrush components derived from the MT-2 and MT-3 tests.

8. Mosaic showing percent covers of sagebrush components derived from the MT-4 and MT-6 tests.

9. Graphs showing mean percent cover of four sagebrush components with different numbers of Landsat scenes.

10. Graphs showing mean root mean square error and square of correlation coefficient values for four sagebrush component predictions derived from extrapolating training data from a single Landsat scene to different numbers of Landsat scenes. 


\section{Tables}

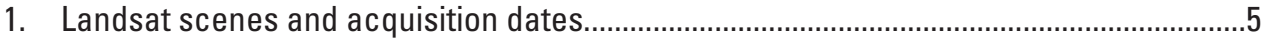

2. QuickBird scenes used in the 2006 sagebrush products ................................................

3. QuickBird test for percent cover of bare-ground..........................................................

4. QuickBird test for percent cover of herbaceous...............................................................

5. QuickBird test for percent cover of sagebrush .............................................................

6. QuickBird test for percent cover of shrub.....................................................................

7. Multiple Landsat scene test for bare-ground in each mosaic that has different number of paths and rows ..........................................................................................

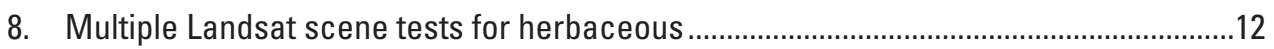

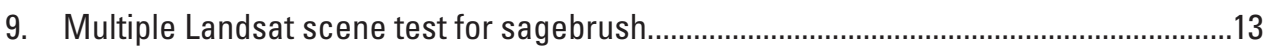

10. Multiple Landsat scene tests for herbaceous .............................................................13

11. Bare-ground comparison using two Landsat scenes across multiple ecological

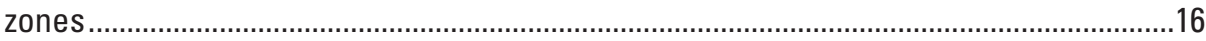

12. Herbaceous comparison using two Landsat scenes across multiple ecological

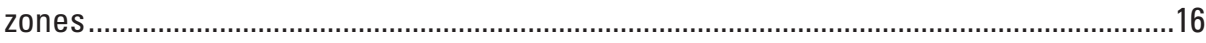

13. Sagebrush comparison using two Landsat scenes across multiple ecological

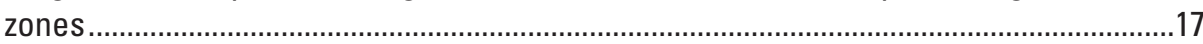

14. Shrub comparison using two Landsat scenes across multiple ecological zones..........17 


\title{
Producing Fractional Rangeland Component Predictions in a Sagebrush Ecosystem, a Wyoming Sensitivity Analysis
}

\author{
By George Xian', Collin Homer ${ }^{2}$, Brian Granneman ${ }^{3}$, and Debbie Meyer ${ }^{3}$
}

\section{Introduction}

Remote sensing information has been widely used to monitor vegetation condition and variations in a variety of ecosystems, including shrublands. Careful application of remotely sensed imagery can provide additional spatially explicit, continuous, and extensive data on the composition and condition of shrubland ecosystems. Historically, the most widely available remote sensing information has been collected by Landsat, which has offered large spatial coverage and moderate spatial resolution data globally for nearly three decades. Such medium-resolution satellite remote sensing information can quantify the distribution and variation of terrestrial ecosystems. Landsat imagery has been frequently used with other high-resolution remote sensing data to classify sagebrush components and quantify their spatial distributions (Ramsey and others, 2004; Seefeldt and Booth, 2004; Stow and others, 2008; Underwood and others, 2007). Modeling algorithms have been developed to use field measurements and satellite remote sensing data to quantify the extent and evaluate the quality of shrub ecosystem components in large geographic areas (Homer and others, 2009). The percent cover of sagebrush ecosystem components, including bare-ground, herbaceous, litter, sagebrush, and shrub, have been quantified for entire western states (Homer and others, 2012). Furthermore, research has demonstrated the use of current measurements with historical archives of Landsat imagery to quantify the variations of these components for the last two decades (Xian and others, 2012).

The modeling method used to quantify the extent and spatial distribution of sagebrush components over a large area also has required considerable amounts of training data to meet targeted accuracy requirements. These training data have maintained product accuracy by ensuring that they are derived

\footnotetext{
${ }^{1}$ ARTS, contractor to the U.S. Geological Survey (USGS) Earth Resources Observation and Science Center, Sioux Falls, SD 57198, USA. Work performed under USGS contract G08PC91508.

${ }^{2}$ USGS Earth Resources Observation and Science Center, Sioux Falls, SD 57198, USA.

${ }^{3}$ SGT, contractor to the USGS Earth Resources Observation and Science Center, Sioux Falls, SD 57198, USA. Work performed under USGS contract G10PC00044.
}

from good quality field measurements collected during appropriate ecosystem phenology and subsequently maximized by extrapolation on high-resolution remote sensing data (Homer and others, 2012). This method has proven its utility; however, to develop these products across even larger areas will require additional cost efficiencies to ensure that an adequate product can be developed for the lowest cost possible. Given the vast geographic extent of shrubland ecosystems in the western United States, identifying cost efficiencies with optimal training data development and subsequent application to medium resolution satellite imagery provide the most likely areas for methodological efficiency gains.

The primary objective of this research was to conduct a series of sensitivity tests to evaluate the most optimal and practical way to develop Landsat scale information for estimating the extent and distribution of sagebrush ecosystem components over large areas in the conterminous United States. An existing dataset of sagebrush components developed from extensive field measurements, high-resolution satellite imagery, and medium resolution Landsat imagery in Wyoming was used as the reference database (Homer and others, 2012). Statistical analysis was performed to analyze the relation between the accuracy of sagebrush components and the amount and distribution of training data on Landsat scenes needed to obtain accurate predictions.

\section{Design of the Sensitivity Tests}

\section{Background on Component Measurement Methods}

The sagebrush ecosystem components were estimated in Wyoming using 2006 Landsat imagery supported by many QuickBird images, which have a spatial resolution of 2.4 meters (m), (Homer and others, 2012). Field measurements were first collected from selected sites, and then combined into a first phase training dataset with a resolution sufficient for training QuickBird imagery. Generally, 60-75 field measurements were collected within one QuickBird footprint, which has a spatial extent of approximately 100 square kilometers $\left(\mathrm{km}^{2}\right)$, for the 2006 Wyoming product. Field measurements 
representing the percent cover of each component (the portion of a ground unit covered by the component) were upscaled for creating regression models to derive a component prediction for each pixel of the QuickBird imagery for each component with regression tree algorithms. QuickBird image predictions were then rescaled to match Landsat resolution and serve as second phase training data to train the regression tree models with Landsat imagery. Unique Landsat regression tree models are required for each sagebrush component. Landsat imagery from spring, summer, and fall along with other derivatives including digital elevation model (DEM), slope, aspect, and three spectral indexes were used as independent variables to create the regression tree models. Four to seven QuickBird scenes were used to train one Landsat scene, and a total of seven Landsat images were used to cover the extent of Wyoming.

The accuracy of the sagebrush component prediction in Wyoming depends highly on the quality of training datasets used for the regression tree models; however, the quantities of training data needed to obtain accurate estimates for the sagebrush components are not certain. It is important, therefore, to understand the sensitivity of the size and spatial distribution of training data on the accuracy of sagebrush component distributions. The requirements of the size of field measurement were discussed in a previous study (Homer and others, 2009). The main focus of this sensitivity testing is to explore the quantities of both field data and high-resolution images required to achieve relatively accurate sagebrush distribution estimates with the use of medium resolution Landsat data. The first focus was to measure the sensitivity of the first phase training data including field dataset collection and high-resolution training data size. The second focus was to evaluate the sensitivity of using multiple instead of single Landsat scenes to extrapolate sagebrush component predictions derived with training datasets from high-resolution imagery. Four sensitivity tests were done: (1) the optimal number of high-resolution QuickBird images needed to create the training dataset in one Landsat scene; (2) the number of Landsat scenes in a mosaic that could be used in one ecological zone with limited training datasets; (3) the sensitivity of using Landsat scene mosaics across different ecological zones with limited training datasets; and (4) the sensitivity of the QuickBird prediction to the number of field plots used for training datasets.

\section{QuickBird Scene Training Sensitivity}

In the Wyoming sagebrush component prediction research, high-resolution QuickBird imagery was used with field observations to build the second phase training data for Landsat regression tree models. The fractional cover of four sagebrush components including bare-ground, herbaceous, sagebrush, and shrub was estimated. A series of tests was done to determine the minimum number of QuickBird scenes that would be needed as training datasets to achieve satisfactory predictions on one Landsat scene. For each sagebrush component, the prediction derived using all available QuickBird scenes $\left(Q_{n}\right)$ in the footprint of a Landsat scene were used as the reference database. The percent cover of the same component was then reproduced with the number of QuickBird scenes varying from 1 to $Q_{n}-1$ using regression tree algorithms and the same independent inputs as in the 2006 product. By using a randomly stratified approach, 1,000 points were selected to acquire the percent cover of the component from the reference dataset and the reproduced dataset to enable comparison. Statistical analyses including regression and a statistical hypothesis test (t-test) for pairing of two sample means were performed to compare the difference in the mean of the two datasets. Root mean square error (RMSE), square of correlation coefficient $\mathrm{r}^{2}$ value, and significance level were included in the statistical analysis. Similar analyses were carried out for all four components. The Landsat scene of path 37/row 31 (p37/r31) was selected for the test, in which $\mathrm{Q}_{\mathrm{n}}$ equals 4 for the original estimates. The locations of the QuickBird scenes used in the Landsat footprint are shown in figure 1.

\section{QuickBird Field Training Sample Size Sensitivity}

The method to evaluate the sensitivity of numbers of high-resolution imagery used for the second phase training dataset was discussed in QuickBird Scene Training Sensitivity section. This test was designed to determine the number of field plots required for optimal first phase training of the QuickBird predictions. Training samples were acquired from $\mathrm{p} 37 / \mathrm{r} 31, \mathrm{p} 36 / \mathrm{r} 30$, and $\mathrm{p} 36 / \mathrm{r} 29$ to produce estimates for all four sagebrush components and were compared with the 2006 products. In $\mathrm{p} 37 / 31$, the 2006 product was produced by using four QuickBird scenes. In p36/r30, five QuickBird scenes were used to form the second phase training dataset. In p36/r29, three QuickBird scenes were selected to produce the second phase training dataset. In every QuickBird footprint, more than 60 field measurements were collected, except for two QuickBird scenes in p36/r29 and p36/r30, where only 50 samples were collected to produce 2006 products. Three QuickBird scenes were selected in each Landsat footprint for this test. The three selected QuickBird scenes contain the second phase training datasets derived by using regression models with the best, worst, and average modeling performances. In each QuickBird footprint, 10 to 50 field samples were selected to re-estimate percent covers of sagebrush components, except in p36/r28, where 10 to 40 samples were acquired. Statistical analyses were conducted to evaluate the similarity and difference between the re-estimate and 2006 products for bareground and shrub.

\section{Landsat Mosaic Evaluation}

The percent covers of sagebrush components were predicted using Landsat imagery with different numbers of QuickBird scenes as the second phase training datasets within 


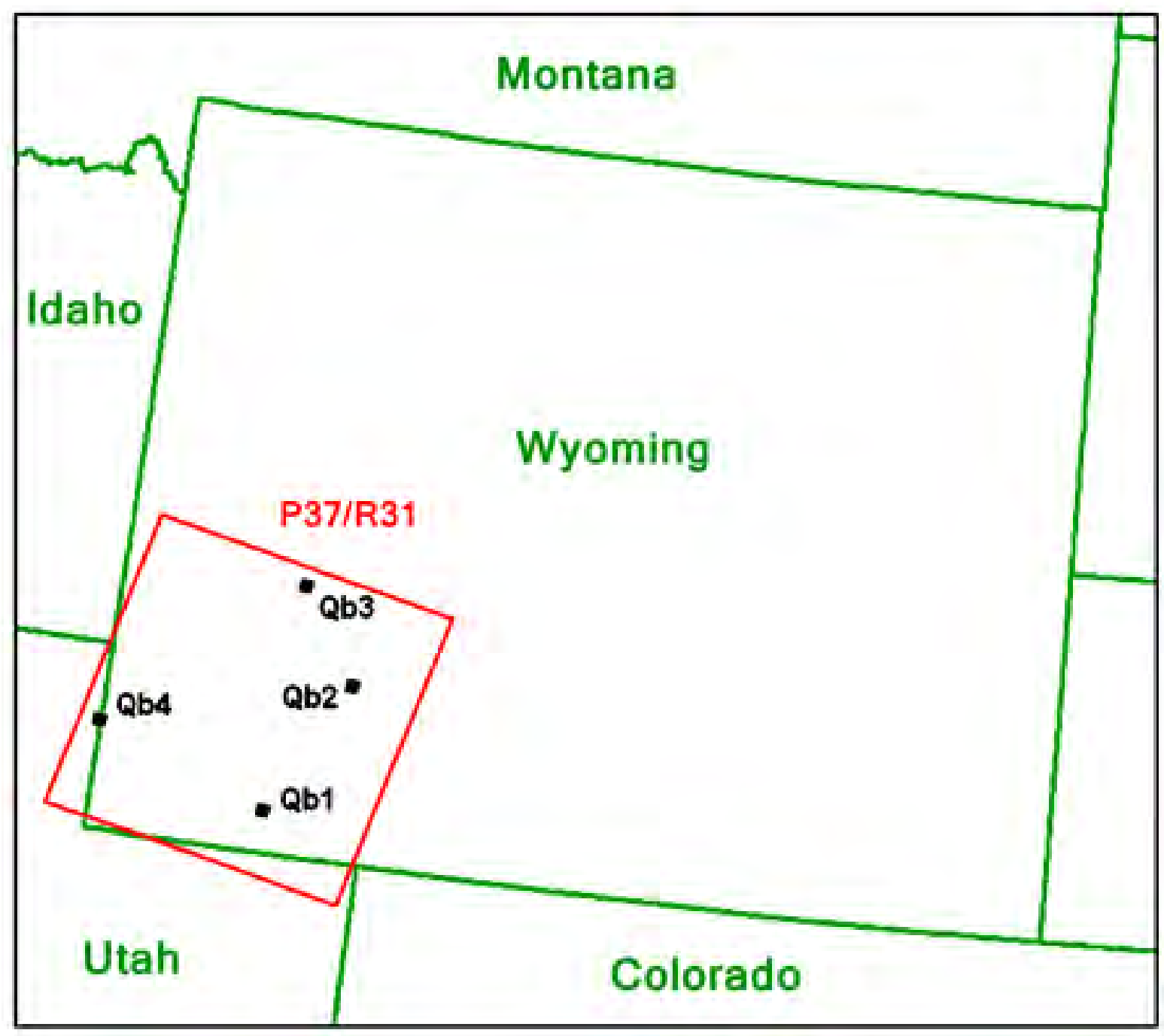

Figure 1. The extent of Landsat $\mathrm{p} 37 / \mathrm{r} 31$ and locations of QuickBird images. The four QuickBird images that are labeled as $\mathrm{Qb} 1, \mathrm{Qb2}, \mathrm{Qb} 3$, and $\mathrm{Qb} 4$ are used as second phase training datasets.

a Landsat footprint in the 2006 product. Because sagebrush components have many similar characteristics in the same ecological region, including the type, density, height, and age, this test was designed to evaluate the possibility of using the second phase training data in one Landsat scene to extrapolate predictions of sagebrush components in a larger area covered by multiple adjacent Landsat scenes.

The sensitivity analyses consisted of four different tests named MT-2, MT-3, MT-4, and MT-6 representing 2, 3, 4, and 6, Landsat scene mosaics. The spatial extents of these tests are shown in figure 2 and acquisition dates for Landsat scenes used for the test are listed in table 1. In the MT-2 test, the second phase training datasets derived from four QuickBird images within the footprint of Landsat p37/r31 were selected as the reference training data. The reference datasets were then used with a two-scene Landsat mosaic to create regression models. Other input data were the same as used in the 2006 product; therefore, the percent covers of sagebrush components were reproduced in the area covered by two Landsat footprints. The MT-3 test is similar to the MT-2, with the use of the reference training data limited in only Landsat p37/r31. The re-estimates of the percent cover of sagebrush components were conducted in a larger area covered by a three-scene Landsat mosaic. Similarly, the MT-4 and MT-6 tests were performed using the same approach but with fourand six-scene Landsat mosaics, respectively. The number of QuickBird scenes used in each Landsat path and row in the 2006 products is shown in table 2 . Statistical analyses were conducted for all tests by comparing the re-estimate products with the 2006 reference products. There were 1,000 samples collected from the 2006 product and the reproduced estimate that were used to acquire magnitudes of the percent cover of sagebrush components. These randomly selected points distributed in each individual Landsat footprint were produced by using the randomly stratified approach. Statistical parameters, including RMSE, $\mathrm{r}^{2}$, and significant level of correlation, were 


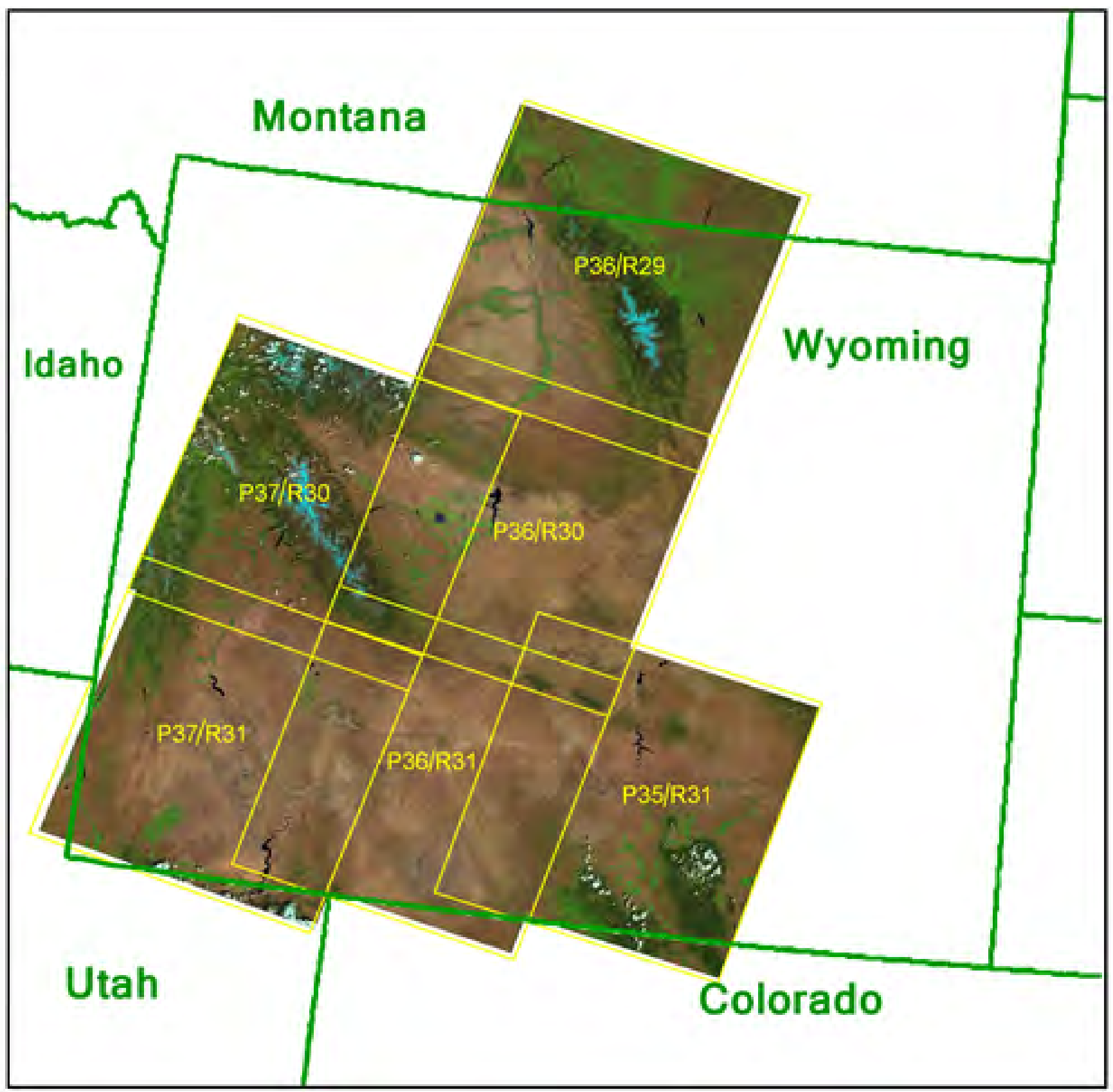

Figure 2. The spatial extent of sensitivity tests with 2 (p37/r31 and p37/r30) (MT-2 test); 3 (p37/r31, p37/r30, and p36/r31) (MT-3 test); 4 (p37/r31, p37/r30, p36/r31, and p36/r30) (MT-4 test); and 6 (p37/r31, p37/r30, P36/R31, p36/r30, p35/r31, and p36/r29) (MT-6 test) Landsat scenes mosaic.

calculated and analyzed to measure the similarity and difference of the reference and re-estimate products. The scenes used were restricted to the same ecological zone as much as possible.

\section{Landsat Mosaic Evaluation Across Different Ecological Zones}

This test was designed to use a two-scene Landsat mosaic that stratifies different ecological zones. The intent was to test how well prediction extrapolation would succeed across multiscene mosaics that cover multiple ecological zones, whereas prediction models were being trained using the second phase dataset in just one Landsat footprint. For this testing, two 
Table 1. Landsat scenes and acquisition dates.

\begin{tabular}{cccc}
\hline Path/row & Spring acquisition date & Summer acquisition date & Fall acquisition date \\
\hline p35/r31 & $5 / 16 / 2006$ & $7 / 06 / 2007$ & $9 / 05 / 2006$ \\
p36/r29 & $4 / 21 / 2006$ & $6 / 29 / 2008$ & $9 / 15 / 2007$ \\
p36/r30 & $4 / 21 / 2006$ & $7 / 31 / 2008$ & $9 / 12 / 2006$ \\
p36/r31 & $4 / 21 / 2006$ & $7 / 31 / 2008$ & $9 / 12 / 2006$ \\
p37/r30 & $5 / 14 / 2006$ & $6 / 18 / 2007$ & $9 / 03 / 2006$ \\
p37/r31 & $5 / 14 / 2006$ & $7 / 17 / 2006$ & $9 / 03 / 2006$ \\
\hline
\end{tabular}

Table 2. QuickBird scenes used in the 2006 sagebrush products.

\begin{tabular}{ccccccc}
\hline Path/row & $\mathbf{p 3 5 / \mathbf { r 3 1 }}$ & $\mathbf{p 3 6 / \mathbf { r 2 9 }}$ & $\mathbf{p 3 6 / \mathbf { r 3 0 }}$ & $\mathbf{p 3 6 / \mathbf { r 3 1 }}$ & $\mathbf{p 3 7 / \mathbf { r 3 0 }}$ & $\mathbf{p 3 7 / \mathbf { r 3 1 }}$ \\
\hline $\begin{array}{c}\text { Number of } \\
\text { QuickBird } \\
\text { scenes }\end{array}$ & 6 & 4 & 7 & 6 & 6 & 4 \\
\hline
\end{tabular}

separate two-scene mosaics were created. For the first test (ET-1), two scenes, $\mathrm{p} 35 / \mathrm{r} 30$, and $\mathrm{p} 35 / \mathrm{r} 31$ were mosaicked. Training data from $\mathrm{p} 35 / \mathrm{r} 31$ were used to make the predictions. For the second test (ET-2), p36/r29, was merged with p37/r29 with training data coming from the former scene. The Landsat scene extents and ecological zones are shown in figure 3. In the ET-1 test, the second phase training data were used with the two-scene mosaics to reproduce the percent cover of sagebrush components for the area of two Landsat footprints. Similarly, in the ET-2 test, the second phase training data were used with the two-scene mosaics to extrapolate the percent cover for components within the two Landsat footprints.

Statistical analyses were conducted for both ET-1 and ET-2 products. These analyses used 1,000 samples that were acquired from randomly selected points. Magnitudes of RMSE, $\mathrm{r}^{2}$, and significant level were derived by comparing cover values of different components from the 2006 products against the reproduced estimates from the ET- 1 and ET-2 predictions.

\section{Results}

\section{QuickBird Scene Test}

The sensitivities from using various numbers of second phase training datasets derived from QuickBird scenes to estimate the percent cover of sagebrush components with Landsat scenes $\mathrm{p} 37 / \mathrm{r} 31$ and $\mathrm{p} 36 / \mathrm{r} 30$ are presented in tables 3-6. Generally, the means obtained from using less than all reference QuickBird scenes are slightly less than the reference values for bare-ground cover and larger for other components. The correlations show that bare-ground and sagebrush have relatively large $\mathrm{r}^{2}$ values, whereas shrub and herbaceous have relatively smaller $\mathrm{r}^{2}$ values. The comparison of the mean percent cover between the 2006 products and the re-estimates suggests those with fewer QuickBird scenes may be slightly overestimating herbaceous, sagebrush, and shrub. However, the magnitudes of RMSE and $\mathrm{r}^{2}$ derived from using fewer reference QuickBird scenes do not show substantial differences between re-estimate and reference products for all sagebrush components. Furthermore, the t-test results indicate that the means of the reference and re-estimate products have no significant differences for all components.

Spatial distributions of the percent cover of four sagebrush components from re-estimates are shown in figure 4, which were produced using one to three QuickBird scenes (fig. 4a-ll), and from 2006 products (fig. 4 (m)-(p)), which were produced using the training data from four QuickBird scenes. Compared with the 2006 products, the re-estimates capture most of the fundamental features of the sagebrush components. For example, the low percent cover of bareground and the high cover of shrub in higher elevation areas are captured in the re-estimates, and the distribution patterns are very similar to the 2006 products.

\section{Training Data Sensitivity}

The magnitudes of RMSE and $\mathrm{r}^{2}$ for each Landsat path and row are evaluated by comparing field samples from the reference and re-estimate products. Figure 5 depicts variations of RMSE and $\mathrm{r}^{2}$ for all four sagebrush components as field samples increase from 10 to 50 in p37/r31 (fig. $5 a-b$ ), p36/r30 (fig. $5 c-d$ ), and p36/r29 (fig. 5e-f). In p37/r31, RMSE apparently decreases after field samples increase to 30 for all components (fig. $5 a$ ). The magnitudes of $\mathrm{r}^{2}$ substantially increase after field samples increased beyond 20 (fig. $5 b$ ). Increasing the number of field samples causes $\mathrm{r}^{2}$ values to increase for all components in all sites except in site 2 for shrub. In p36/r30, magnitudes of RMSE for bare-ground and shrub steadily decrease in 


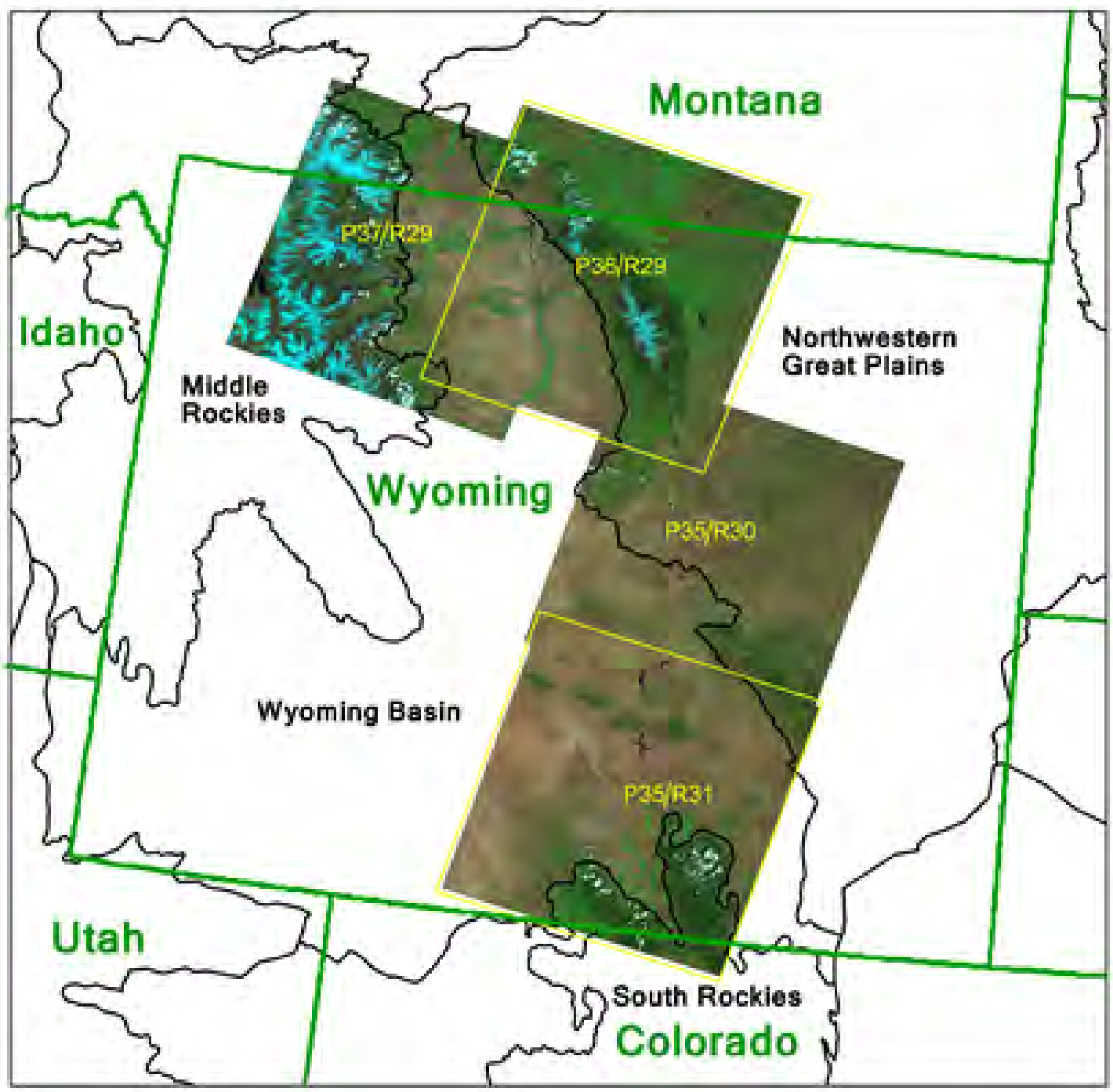

Figure 3. Landsat scenes used for different ecological zone tests. Landsat scenes of $p 35 / r 30$ and $p 35 / r 31$ located in the Wyoming Basin, South Rockies, and Northwestern Great Plains ecological zones are used for the first test (ET-1). Landsat scenes of p37/r29 and p36/r29 located in Wyoming Basin, Middle Rockies, and Northwestern Great Plains ecological zones are used for the second test (ET-2).

Table 3. QuickBird (QB) test for percent cover of bare-ground.

[Values of square of correlation coefficient $\left(\mathrm{r}^{2}\right)$ and root mean square error (RMSE) are listed; N/A, represents data are not available]

\begin{tabular}{lccc}
\hline & $\mathbf{r}^{2}$ & RMSE & Mean \\
\hline 1 QB to 4 QB & 0.696 & 12.64 & 65.52 \\
2 QB to 4 QB & 0.624 & 14.36 & 52.73 \\
3 QB to 4 QB & 0.665 & 13.17 & 56.05 \\
4 QB - reference & N/A & N/A & 61.96 \\
\hline
\end{tabular}


Table 4. QuickBird test for percent cover of herbaceous.

\begin{tabular}{lccc}
\hline & $\mathbf{r}^{2}$ & RMSE & Mean \\
\hline 1 QB to 4 QB & 0.123 & 8.85 & 15.92 \\
2 QB to 4 QB & 0.252 & 8.33 & 15.26 \\
3 QB to 4 QB & 0.245 & 9.20 & 17.14 \\
4 QB - reference & N/A & N/A & 13.23 \\
\hline
\end{tabular}

Table 5. QuickBird test for percent cover of sagebrush.

\begin{tabular}{lccc}
\hline & $\mathbf{r}^{2}$ & RMSE & Mean \\
\hline 1 QB to 4 QB & 0.506 & 3.88 & 9.14 \\
2 QB to 4 QB & 0.667 & 3.56 & 9.32 \\
3 QB to 4 QB & 0.612 & 3.82 & 9.10 \\
4 QB - reference & N/A & N/A & 8.10 \\
\hline
\end{tabular}

Table 6. QuickBird test for percent cover of shrub.

\begin{tabular}{lccc}
\hline & $\mathbf{r}^{2}$ & RMSE & Mean \\
\hline 1 QB to 4 QB & 0.400 & 3.66 & 9.88 \\
2 QB to 4 QB & 0.250 & 5.48 & 13.06 \\
3 QB to 4 QB & 0.371 & 4.28 & 11.56 \\
4 QB - reference & N/A & N/A & 10.49 \\
\hline
\end{tabular}

all sites and become stable after field samples increase beyond 40 samples. Additionally, $\mathrm{r}^{2}$ values for these two components also increase as field samples are increased and become relatively stable with more than 40 samples. Similar trends in both RMSE and $\mathrm{r}^{2}$ are also observed in $\mathrm{p} 36 / \mathrm{r} 29$, although less than 50 samples were analyzed in some sites because the maximum samples used to produce the reference data were 50 in these sites.

The variations of RMSE and $\mathrm{r}^{2}$ in different paths and rows are averaged to review the overall effect of field sample selection. The average RMSE (fig. $6 a$ ) and $\mathrm{r}^{2}$ (fig. $6 b$ ) for bareground and shrub distributions from three scenes' sensitivity tests is depicted in figure 10. The overall average RMSE and $\mathrm{r}^{2}$ follow approximately the same trends as observed in individual path and rows. For bare-ground, RMSE at the 10 field sample mark is 169 percent of the value of the 50 field sample mark, and it declines to 111 percent when 40 field samples are added. The $\mathrm{r}^{2}$ at the 10 field sample mark is 56 percent of the value at the 50 field sample mark, and it increases to 87 percent of the value at the 40 field sample mark. Similarly, ratios of RMSE and $\mathrm{r}^{2}$ at the 10 field sample mark to the 50 field sample mark vary from 160 percent to 100 percent and from 45 percent to 90 percent, respectively, after the 40 field sample mark.

\section{Multiple Landsat Scenes Test}

Spatial distributions are displayed in figures 6 and 7 of four sagebrush components for the 2006 products and reestimates using limited training datasets from the footprint of p37r31 with different Landsat mosaics. All re-estimate sagebrush components in the MT-2 test (fig. $6 e-(h)$ have high agreement with the reference products (fig. $6 a-d$ ) in terms of spatial distribution patterns and cover intensities. The similarities are also observed in the MT-3 test (fig. $6 i-p$ ), except for the bare-ground re-estimate, which has relatively smaller percent covers. No apparent differences between reference (fig. $7 a-d)$ ) and re-estimate (fig. $7 e-h$ ) are observed in the MT-4 test. Apparent differences, especially for shrub distribution, are observed in the MT-6 test (fig. $6 i-p$ ), in which the reference product has relatively larger magnitudes in shrub percent cover (fig. $6 l$ ) than those in the re-estimate (fig. $6 p$ ).

The RMSE and $\mathrm{r}^{2}$ of all components from tests in each path and row are shown in tables 7 though 10 . The 95-percent significance level of a t-test for two pairs of mean is indicated by a * after $\mathrm{r}^{2}$ values. The MT- 2 tests have larger $\mathrm{r}^{2}$ values and smaller RMSE for bare-ground, sagebrush, and shrub, but not for herbaceous; also, t-tests for all components that show correlations of mean values between the reference and re-estimate 

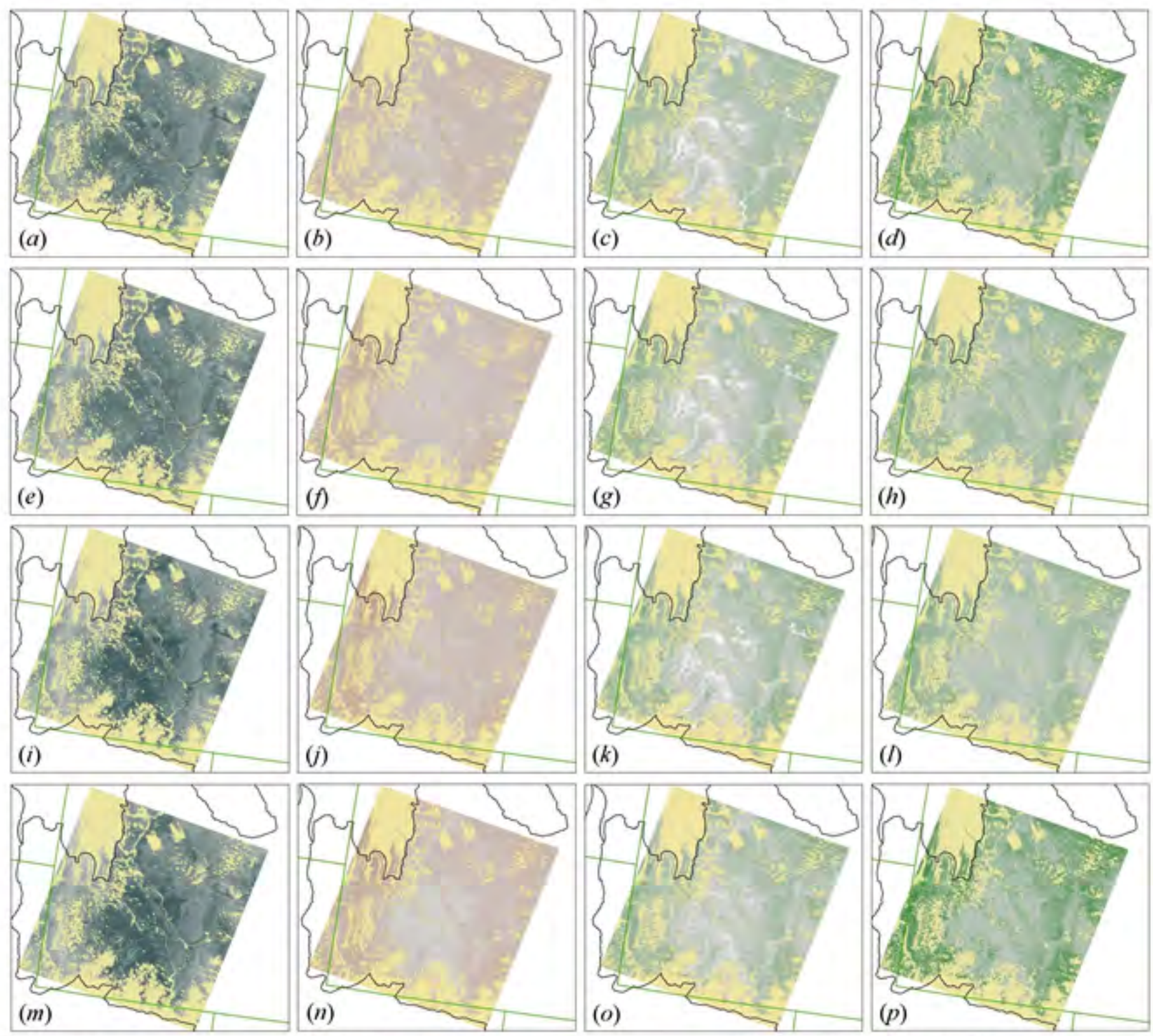

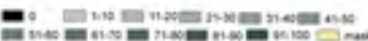

-

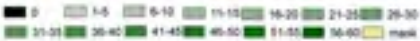

Figure 4. Percent covers of sagebrush components obtained using different numbers of QuickBird imagery. Panels from left to right are bare-ground, herbaceous, sagebrush, and shrub. Panels from top to bottom depict estimates by using one QuickBird scene (a-d), two QuickBird scenes (e-h), three QuickBird scenes (i-l), and four QuickBird scenes (m-p). Numbers in legends represent percent covers of difference components. 

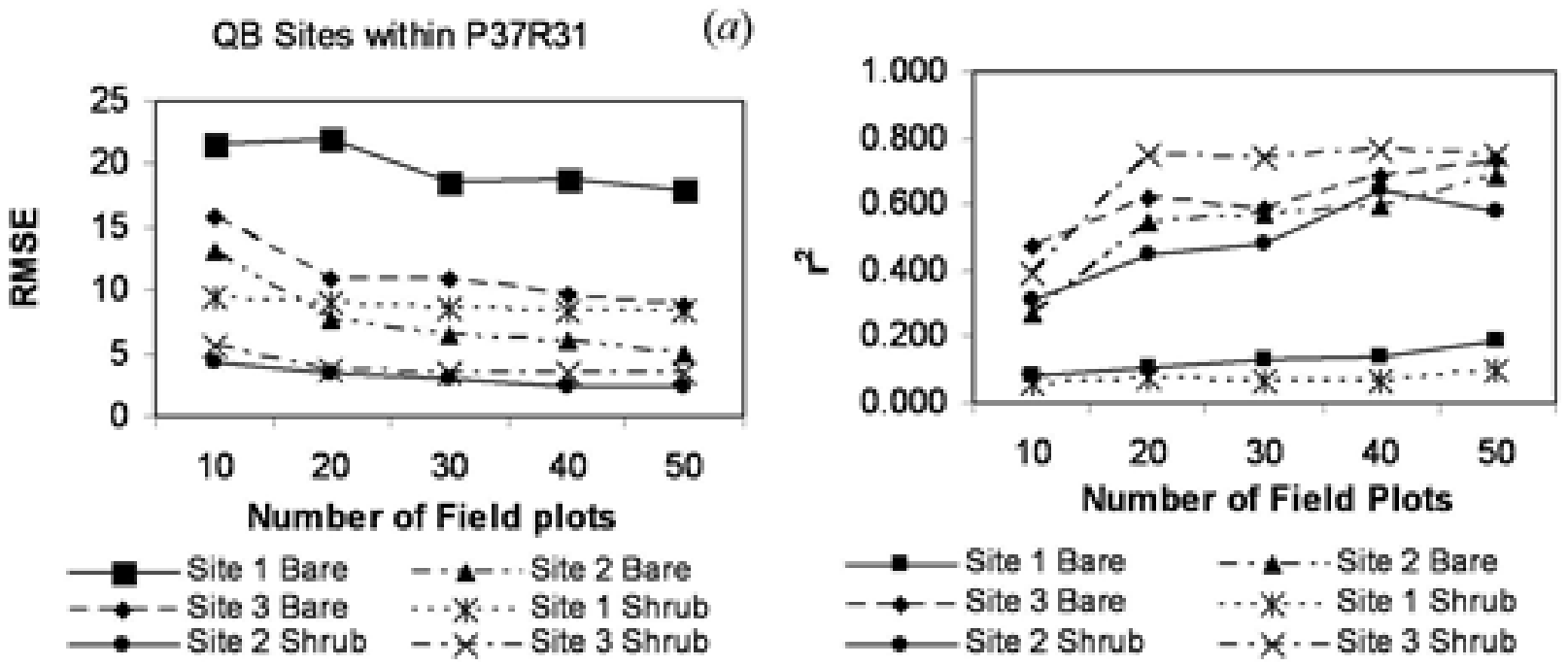

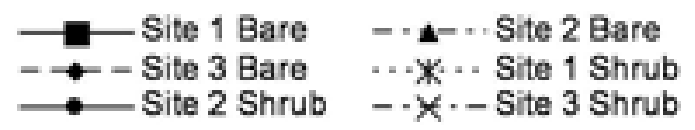

QB Sites within P36R30

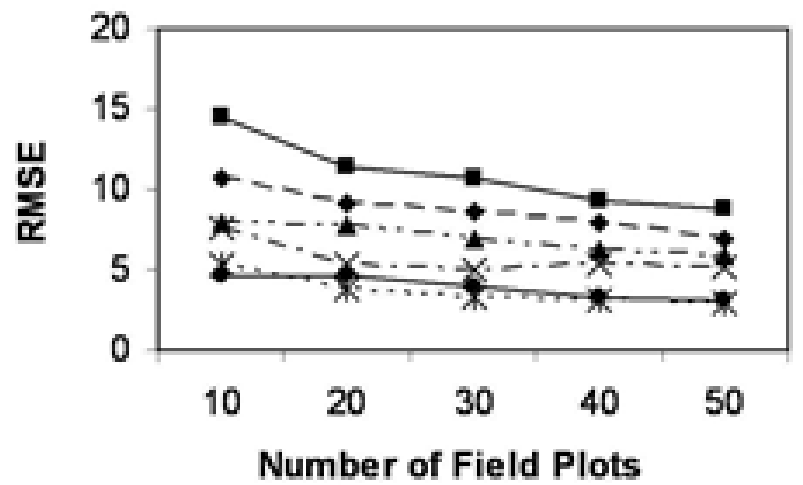

-..-.. Site 7 Bare

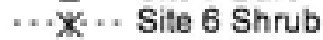

- $*$. - Site 9 Shrub (c)

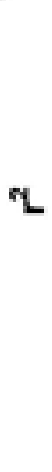

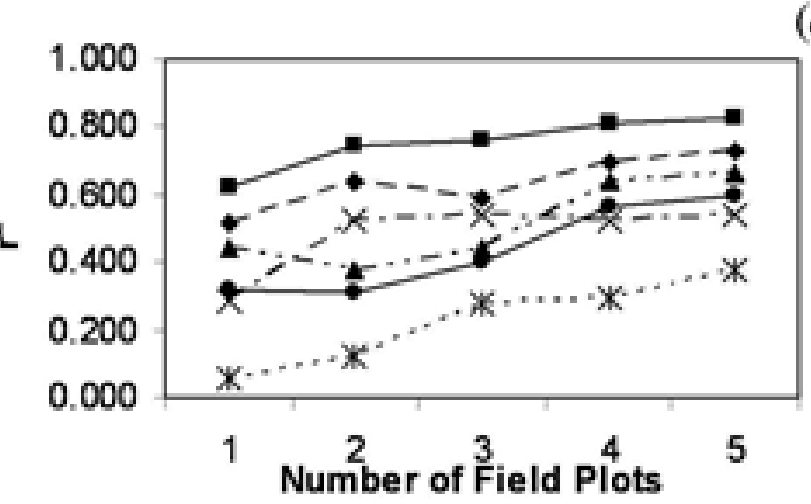

(d)

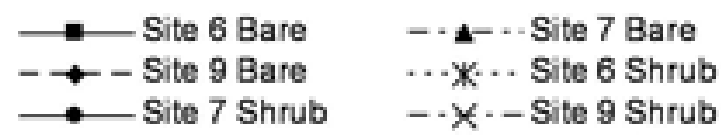

(e)
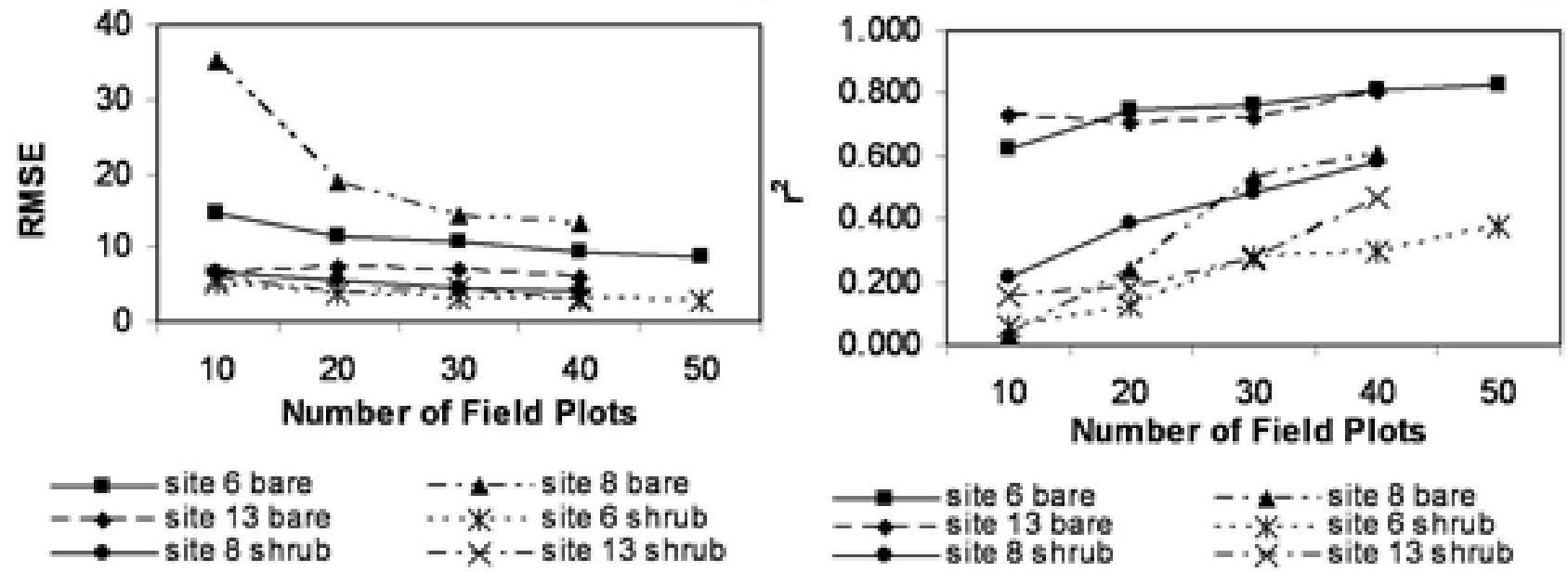

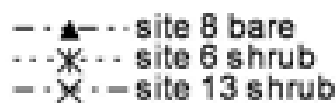

Figure 5. Field sample sensitivity test for three Landsat footprints. Root mean square error (RMSE) and square of correlation coefficient $\left(r^{2}\right)$ are calculated using re-estimate and 2006 products. The 2006 product was produced by using all training sample numbers between 60 and 50. RMSE and $r^{2}$ values are displayed for p37/r31 (a-b), p36/r30 (c-d), and p36/r29 (e-f). 

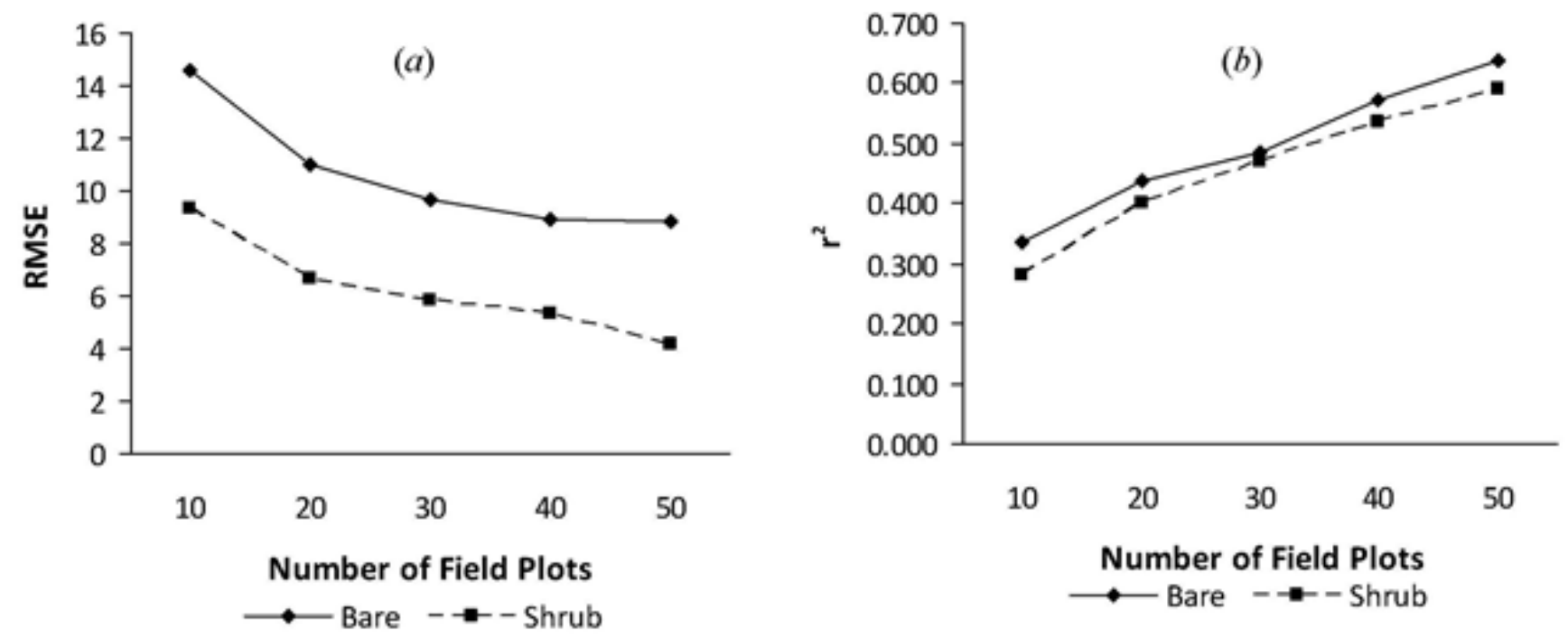

Figure 6. Average root mean square error (RMSE) (a) and $\mathrm{r}^{2}$ (b) by comparing reference and re-estimate datasets for three Landsat path/rows.

products are significant in the MT-2 test. In the MT-3 test, most $\mathrm{r}^{2}$ values are still large and RMSE values are small. All t-tests are significant except for the shrub. In the MT-4 test, all $\mathrm{r}^{2}$ values are reduced from the MT-2 and MT- 3 tests. The t-tests still show most paths and rows are significant for all components. In the MT- 6 test, $\mathrm{r}^{2}$ values are smaller and RMSE values are larger than those in the area that is close to the path 37 and row 31 , which contains the second phase training data.

The RMSE and $\mathrm{r}^{2}$ obtained by using different Landsat scene mosaics are averaged for each Landsat mosaic. These means are used to determine the general correlation between the reference and re-estimate products. The mean covers for all components calculated from each test are shown in figure 8 . The difference trends are modestly higher as the numbers of scenes are increased to more than four but still remain within a reasonable range when comparing the mean percent cover. Mean RMSE and $\mathrm{r}^{2}$ values for all components in the MT test are shown in figure 9. The RMSE shows that herbaceous has a substantial increase after the number of scenes exceeds four (fig. 9a). Similar increasing trends are also demonstrated for sagebrush and shrub. The mean $\mathrm{r}^{2}$ values of bare-ground and herbaceous show substantial decreases as the numbers of scenes are increased by more than two (fig. $10 \mathrm{~b}$ ). The mean $\mathrm{r}^{2}$ for shrub decreased most dramatically after the mosaic had grown to four images in the test while the mean $r^{2}$ for sagebrush declined linearly.

\section{Ecoregion Sensitivity Test}

Values of $\mathrm{r}^{2}$, RMSE, and mean for all components in the ET-1 and ET-2 tests are shown in tables 11 through 14. The $\mathrm{r}^{2}$ values are small except for bare-ground, but the correlations are still significant for all components. The t-tests are significant for all components except for sagebrush in the ET-2 test. The RMSE values suggest that the accuracies of new estimates are relatively high for all components except for sagebrush in the ET-2 test and herbaceous in both ET-1 and ET-2 tests. 

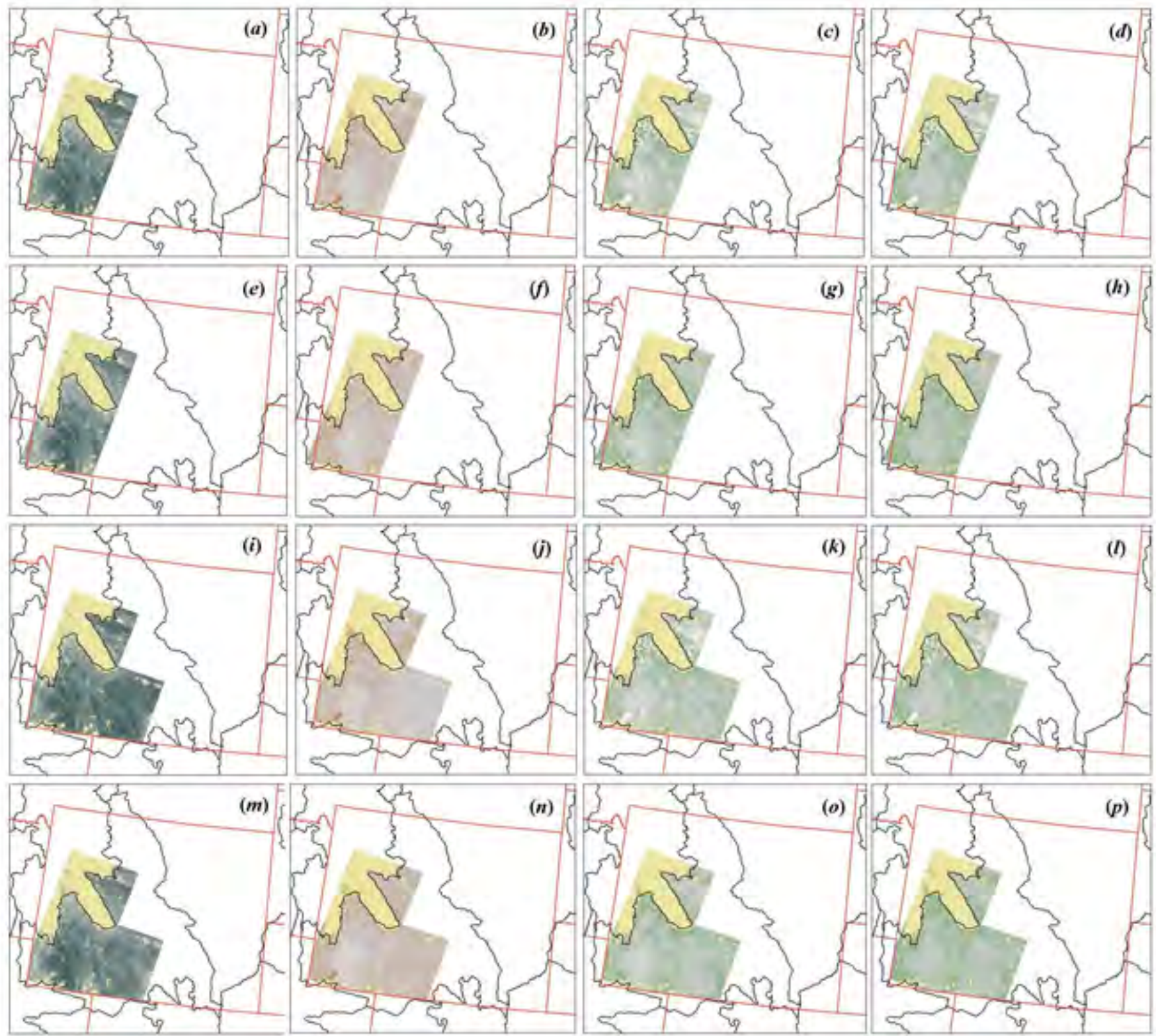

Figure 7. Percent covers of sagebrush components derived from the MT-2 and MT-3 tests. Panels from left to right depict bareground, herbaceous, sagebrush, and shrub. Panels of $(\mathrm{a}-\mathrm{d})$ and $(\mathrm{i}-\mathrm{I})$ are reference sagebrush components. Panels of $(\mathrm{e}-\mathrm{h})$ and $(m-p)$ are sagebrush components obtained by using two (MT-2) and three (MT-3) Landsat scene mosaics estimated with training data from one Landsat scene. The color legends are same as in Figure 4. 


\section{Producing Fractional Rangeland Component Predictions in a Sagebrush Ecosystem, a Wyoming Sensitivity Analysis}

Table 7. Multiple Landsat scene test (MT) for bare-ground in each mosaic that has different number of paths and rows (p/r).

[*, indicates the 95-percent significance level of t-test of two pairs of mean]

\begin{tabular}{cccccc}
\hline Path/row & Statistics & MT-2 & MT-3 & MT-4 & MT-6 \\
\hline \multirow{2}{*}{ p35/r31 } & $\mathrm{r}^{2}$ & $\mathrm{~N} / \mathrm{A}$ & $\mathrm{N} / \mathrm{A}$ & $\mathrm{N} / \mathrm{A}$ & 0.388 \\
& $\mathrm{RMSE}$ & $\mathrm{N} / \mathrm{A}$ & $\mathrm{N} / \mathrm{A}$ & $\mathrm{N} / \mathrm{A}$ & 22.94 \\
$\mathrm{p} 36 / \mathrm{r} 29$ & $\mathrm{r}^{2}$ & $\mathrm{~N} / \mathrm{A}$ & $\mathrm{N} / \mathrm{A}$ & $\mathrm{N} / \mathrm{A}$ & 0.177 \\
& $\mathrm{RMSE}$ & $\mathrm{N} / \mathrm{A}$ & $\mathrm{N} / \mathrm{A}$ & $\mathrm{N} / \mathrm{A}$ & 16.73 \\
$\mathrm{p} 36 / \mathrm{r} 30$ & $\mathrm{r}^{2}$ & $\mathrm{~N} / \mathrm{A}$ & $\mathrm{N} / \mathrm{A}$ & $0.134^{*}$ & $0.137^{*}$ \\
& $\mathrm{RMSE}$ & $\mathrm{N} / \mathrm{A}$ & $\mathrm{N} / \mathrm{A}$ & 17.30 & 27.01 \\
$\mathrm{p} 36 / \mathrm{r} 31$ & $\mathrm{~N} / \mathrm{A}$ & $0.542^{*}$ & 0.443 & $0.486^{*}$ \\
& $\mathrm{r}$ & $\mathrm{N} / \mathrm{A}$ & 18.28 & 20.58 & 18.96 \\
$\mathrm{p} 37 / \mathrm{r} 30$ & $\mathrm{RMSE}$ & $0.625^{*}$ & $0.572^{*}$ & $0.473^{*}$ & $0.477^{*}$ \\
& $\mathrm{r}^{2}$ & 14.31 & 14.67 & 15.35 & 15.30 \\
$\mathrm{p} 37 / \mathrm{r} 31$ & $\mathrm{RMSE}$ & $0.701^{*}$ & $0.685^{*}$ & $0.667^{*}$ & $0.685^{*}$ \\
& $\mathrm{r}^{2}$ & 12.40 & 12.25 & 13.08 & 12.30 \\
\hline
\end{tabular}

Table 8. Multiple Landsat scene tests for herbaceous.

[*, indicates the 95-percent significance level of t-test of two pairs of mean]

\begin{tabular}{cccccc}
\hline Path/row & Statistics & MT-2 & MT-3 & MT-4 & MT-6 \\
\hline \multirow{2}{*}{ p35/r31 } & $\mathrm{r}^{2}$ & $\mathrm{~N} / \mathrm{A}$ & $\mathrm{N} / \mathrm{A}$ & $\mathrm{N} / \mathrm{A}$ & $0.167^{*}$ \\
& $\mathrm{RMSE}$ & $\mathrm{N} / \mathrm{A}$ & $\mathrm{N} / \mathrm{A}$ & $\mathrm{N} / \mathrm{A}$ & 12.30 \\
$\mathrm{p} 36 / \mathrm{r} 29$ & $\mathrm{r}^{2}$ & $\mathrm{~N} / \mathrm{A}$ & $\mathrm{N} / \mathrm{A}$ & $\mathrm{N} / \mathrm{A}$ & $0.177^{*}$ \\
& $\mathrm{RMSE}$ & $\mathrm{N} / \mathrm{A}$ & $\mathrm{N} / \mathrm{A}$ & $\mathrm{N} / \mathrm{A}$ & 41.05 \\
$\mathrm{p} 36 / \mathrm{r} 30$ & $\mathrm{~N} / \mathrm{A}$ & $\mathrm{N} / \mathrm{A}$ & 0.126 & $0.149^{*}$ \\
& $\mathrm{r}$ & $\mathrm{N} / \mathrm{A}$ & $\mathrm{N} / \mathrm{A}$ & 11.60 & 16.73 \\
$\mathrm{p} 36 / \mathrm{r} 31$ & $\mathrm{~N} / \mathrm{A}$ & $0.006^{*}$ & $0.004^{*}$ & $0.013^{*}$ \\
& $\mathrm{r}$ & $\mathrm{N} / \mathrm{A}$ & 10.09 & 9.05 & 9.50 \\
$\mathrm{p} 37 / \mathrm{r} 30$ & $\mathrm{RMSE}$ & $0.031^{*}$ & $0.248^{*}$ & $0.066^{*}$ & $0.033^{*}$ \\
& $\mathrm{r}^{2}$ & 0.52 & 9.66 & 12.36 & 11.53 \\
$\mathrm{p} 37 / \mathrm{r} 31$ & $\mathrm{RMSE}$ & $0.348^{*}$ & $0.293^{*}$ & 0.367 & 0.294 \\
& $\mathrm{r}^{2}$ & 8.31 & 9.84 & 8.63 & 9.00 \\
\hline
\end{tabular}


Table 9. Multiple Landsat scene test for sagebrush.

[*, indicates the 95 -percent significance level of t-test of two pairs of mean]

\begin{tabular}{ccllll}
\hline Path/row & Statistics & MT-2 & MT-3 & MT-4 & MT-6 \\
\hline \multirow{2}{*}{ p35/r31 } & $\mathrm{r}^{2}$ & $\mathrm{~N} / \mathrm{A}$ & $\mathrm{N} / \mathrm{A}$ & $\mathrm{N} / \mathrm{A}$ & $0.068^{*}$ \\
& $\mathrm{RMSE}$ & $\mathrm{N} / \mathrm{A}$ & $\mathrm{N} / \mathrm{A}$ & $\mathrm{N} / \mathrm{A}$ & 8.02 \\
$\mathrm{p} 36 / \mathrm{r} 29$ & $\mathrm{r}^{2}$ & $\mathrm{~N} / \mathrm{A}$ & $\mathrm{N} / \mathrm{A}$ & $\mathrm{N} / \mathrm{A}$ & $0.176^{*}$ \\
& $\mathrm{RMSE}$ & $\mathrm{N} / \mathrm{A}$ & $\mathrm{N} / \mathrm{A}$ & $\mathrm{N} / \mathrm{A}$ & 6.30 \\
$\mathrm{p} 36 / \mathrm{r} 30$ & $\mathrm{r}^{2}$ & $\mathrm{~N} / \mathrm{A}$ & $\mathrm{N} / \mathrm{A}$ & $0.095^{*}$ & 0.014 \\
& $\mathrm{RMSE}$ & $\mathrm{N} / \mathrm{A}$ & $0.571^{*}$ & $0.536^{*}$ & 8.91 \\
$\mathrm{p} 36 / \mathrm{r} 31$ & $\mathrm{r} / \mathrm{A}$ & 3.69 & 3.83 & $0.332^{*}$ \\
& $\mathrm{r}$ & $\mathrm{N} / \mathrm{A}$ & $0.506^{*}$ & $0.454^{*}$ & 4.85 \\
$\mathrm{p} 37 / \mathrm{r} 30$ & $\mathrm{r}^{2}$ & $0.526^{*}$ & 4.98 & 5.11 & $0.412^{*}$ \\
& $\mathrm{RMSE}$ & 5.04 & $0.481^{*}$ & $0.476^{*}$ & 5.12 \\
$\mathrm{p} 37 / \mathrm{r} 31$ & $\mathrm{r}^{2}$ & $0.514^{*}$ & 4.66 & 4.75 & $0.594^{*}$ \\
\end{tabular}

Table 10. Multiple Landsat scene tests for herbaceous.

[*, indicates the 95-percent significance level of t-test of two pairs of mean]

\begin{tabular}{ccllll}
\hline Path/row & Statistics & MT-2 & MT-3 & MT-4 & MT-6 \\
\hline \multirow{2}{*}{ p35/r31 } & $\mathrm{r}^{2}$ & $\mathrm{~N} / \mathrm{A}$ & $\mathrm{N} / \mathrm{A}$ & $\mathrm{N} / \mathrm{A}$ & $0.093^{*}$ \\
& $\mathrm{RMSE}$ & $\mathrm{N} / \mathrm{A}$ & $\mathrm{N} / \mathrm{A}$ & $\mathrm{N} / \mathrm{A}$ & 6.82 \\
$\mathrm{p} 36 / \mathrm{r} 29$ & $\mathrm{r}^{2}$ & $\mathrm{~N} / \mathrm{A}$ & $\mathrm{N} / \mathrm{A}$ & $\mathrm{N} / \mathrm{A}$ & $0.176^{*}$ \\
& $\mathrm{RMSE}$ & $\mathrm{N} / \mathrm{A}$ & $\mathrm{N} / \mathrm{A}$ & $\mathrm{N} / \mathrm{A}$ & 6.61 \\
$\mathrm{p} 36 / \mathrm{r} 30$ & $\mathrm{r}^{2}$ & $\mathrm{~N} / \mathrm{A}$ & $\mathrm{N} / \mathrm{A}$ & $0.134^{*}$ & 0.046 \\
& $\mathrm{RMSE}$ & $\mathrm{N} / \mathrm{A}$ & $\mathrm{N} / \mathrm{A}$ & 7.29 & 8.62 \\
$\mathrm{p} 36 / \mathrm{r} 31$ & $\mathrm{~N} / \mathrm{A}$ & 0.414 & 0.412 & 0.216 \\
& $\mathrm{r}$ & $\mathrm{N} / \mathrm{A}$ & 4.18 & 4.25 & 5.46 \\
$\mathrm{p} 37 / \mathrm{r} 30$ & $\mathrm{RME}$ & $0.456^{*}$ & $0.413^{*}$ & $0.441^{*}$ & $0.434^{*}$ \\
& $\mathrm{r}$ & 5.19 & 4.48 & 4.12 & 5.45 \\
$\mathrm{p} 37 / \mathrm{r} 31$ & $\mathrm{RMSE}$ & $0.571^{*}$ & $0.572^{*}$ & $0.555^{*}$ & $0.572^{*}$ \\
& $\mathrm{r}$ & 4.32 & 4.31 & 4.44 & 4.25 \\
\hline
\end{tabular}



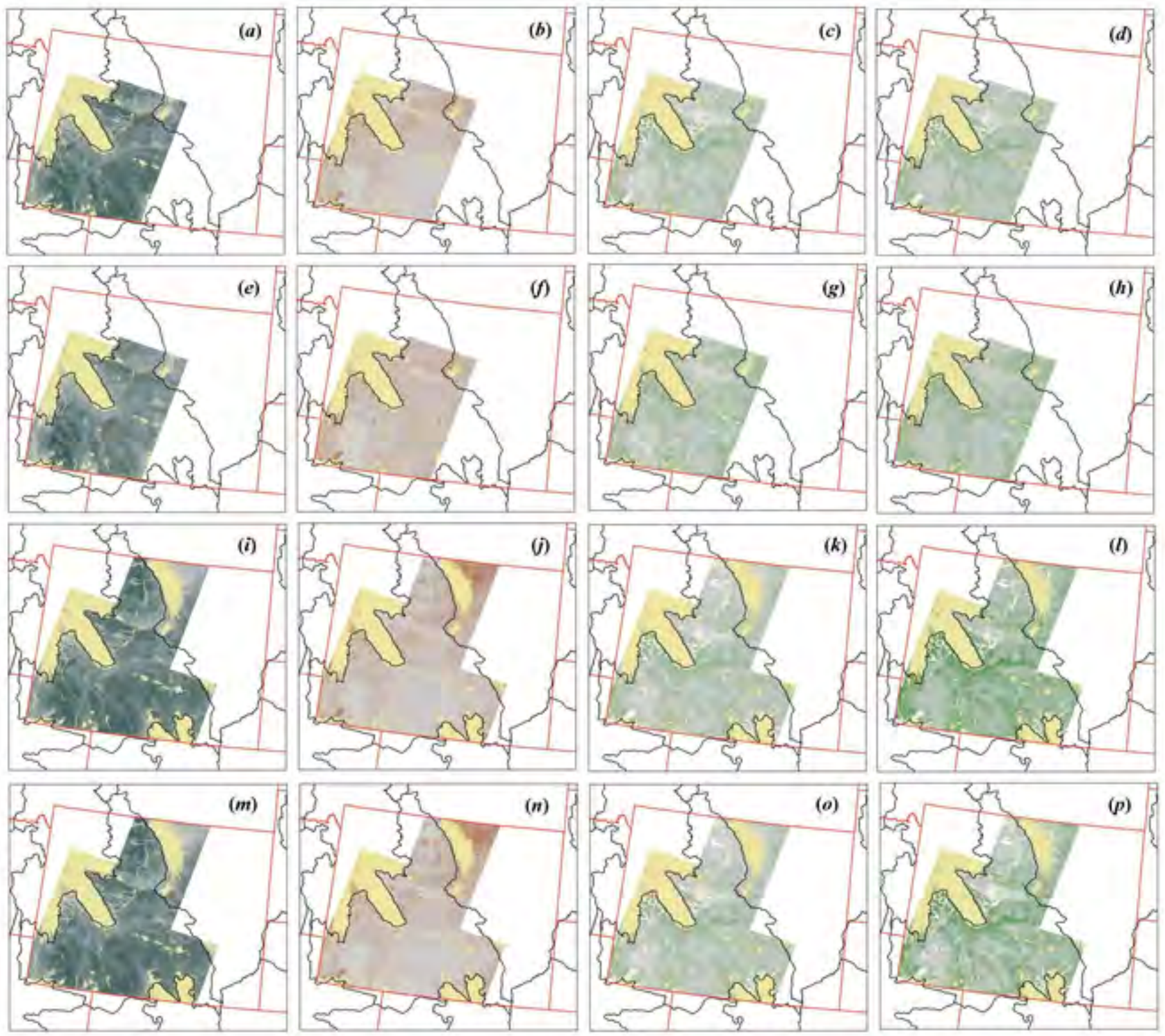

Figure 8. Percent covers of sagebrush components derived from the MT-4 and MT-6 tests. Panels from left to right depict bareground, herbaceous, sagebrush, and shrub. Panels of $(a-d)$ and $(i-l)$ are reference sagebrush components. Panels of $(e-h)$ and $(m-p)$ are sagebrush components obtained by using four (MT-4) and six (MT-6) Landsat scene mosaics estimated with training data from one Landsat scene. The color legends are same as in Figure 4. 


\section{Bare ground}
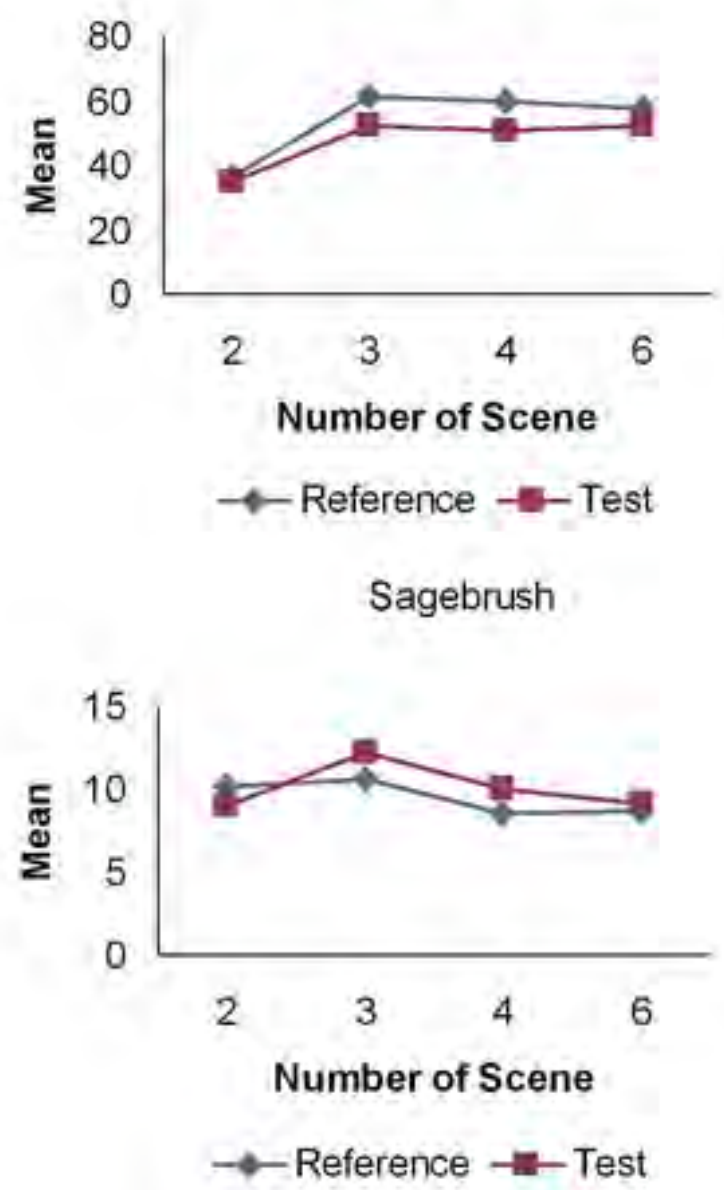

Herbaceous
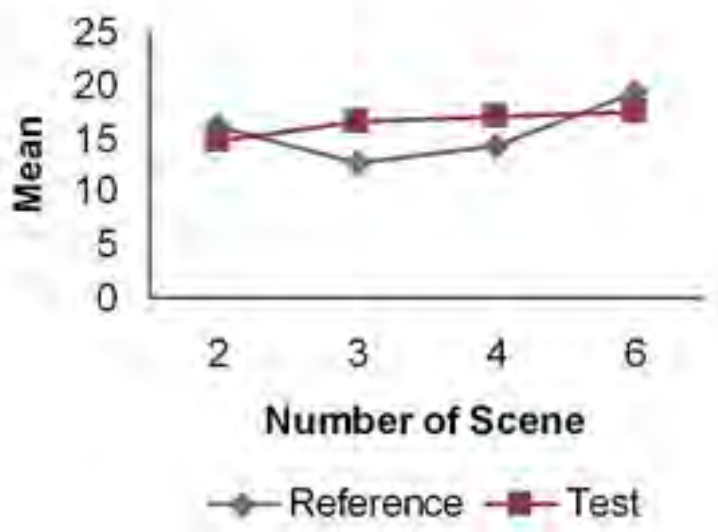

Shrub

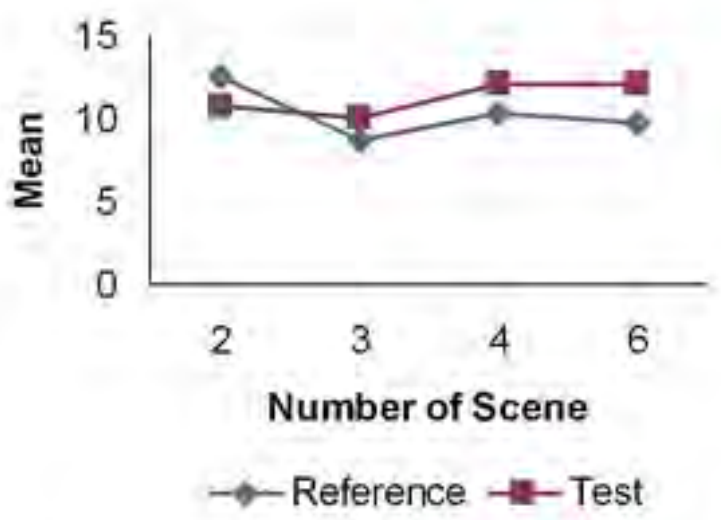

Figure 9. Mean percent cover of four sagebrush components with different numbers of Landsat scenes. The $x$-axis is the number of Landsat scenes. The $y$-axis is the mean value. The reference is for the 2006 products and test is for the new estimates. 


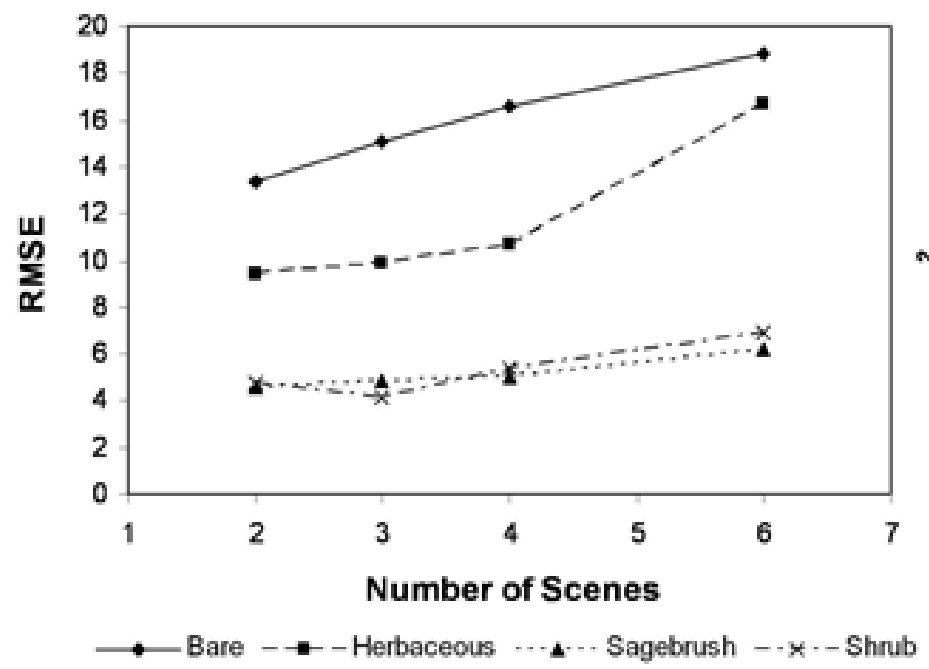

(a)

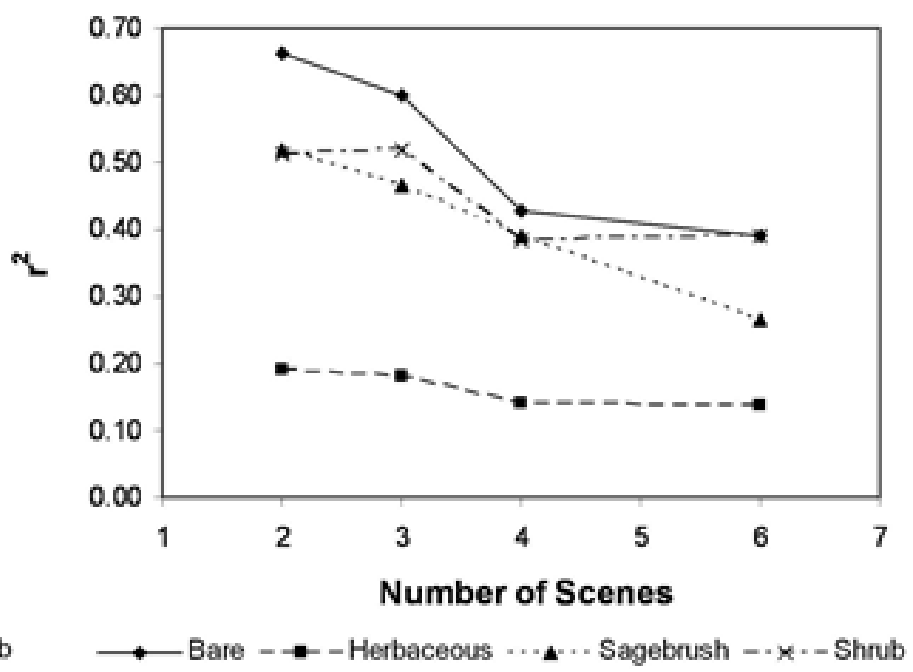

(b)

Figure 10. Mean root mean square error (RMSE) and square of correlation coefficient $\left(\mathrm{r}^{2}\right)$ values for four sagebrush component predictions derived from extrapolating training data from a single Landsat scene to different numbers of Landsat scenes.

Table 11. Bare-ground comparison using two Landsat scenes across multiple ecological zones.

[*, indicates the 95-percent significance level of t-test of two pairs of mean; ET-1 and ET-2 represents tests in one and two ecological zones]

\begin{tabular}{|c|c|c|c|c|}
\hline \multirow[b]{2}{*}{ Statistics } & \multicolumn{2}{|c|}{ ET-1 } & \multicolumn{2}{|c|}{ ET-2 } \\
\hline & p35/r30 & p35/r31 & p37/r29 & p36/r29 \\
\hline $\mathrm{r}^{2}$ & $0.367 *$ & N/A & $0.528 *$ & N/A \\
\hline Mean & 49.16 & 54.96 & 63.09 & 61.53 \\
\hline
\end{tabular}

Table 12. Herbaceous comparison using two Landsat scenes across multiple ecological zones

$[*$, indicates the 95-percent significance level of t-test of two pairs of mean; ET-1 and ET-2 represents tests in one and two ecological zones]

\begin{tabular}{|c|c|c|c|c|}
\hline \multirow[b]{2}{*}{ Statistics } & \multicolumn{2}{|c|}{ ET-1 } & \multicolumn{2}{|c|}{ ET-2 } \\
\hline & p35/r30 & p35/r31 & p37/r29 & p36/r29 \\
\hline$r^{2}$ & $0.204^{*}$ & N/A & $0.286^{*}$ & N/A \\
\hline Mean & 24.23 & 13.71 & 14.47 & 15.32 \\
\hline
\end{tabular}


Table 13. Sagebrush comparison using two Landsat scenes across multiple ecological zones

[*, indicates the 95-percent significance level of t-test of two pairs of mean; ET-1 and ET-2 represents tests in one and two ecological zones]

\begin{tabular}{|c|c|c|c|c|}
\hline \multirow[b]{2}{*}{ Statistics } & \multicolumn{2}{|c|}{ ET-1 } & \multicolumn{2}{|c|}{ ET-2 } \\
\hline & p35/r30 & p35/r31 & p37/r29 & p36/r29 \\
\hline$r^{2}$ & $0.204^{*}$ & N/A & 0.471 & N/A \\
\hline RMSE & 5.19 & N/A & 2.43 & N/A \\
\hline Mean & 8.69 & 10.54 & 4.56 & 4.48 \\
\hline
\end{tabular}

Table 14. Shrub comparison using two Landsat scenes across multiple ecological zones

[*, indicates the 95-percent significance level of t-test of two pairs of mean; ET-1 and ET-2 represents tests in one and two ecological zones]

\begin{tabular}{|c|c|c|c|c|}
\hline \multirow[b]{2}{*}{ Statistics } & \multicolumn{2}{|c|}{ ET-1 } & \multicolumn{2}{|c|}{ ET-2 } \\
\hline & p35/r30 & p35/r31 & p37/r29 & p36/r29 \\
\hline $\mathrm{r}^{2}$ & $0.206^{*}$ & N/A & $0.242 *$ & N/A \\
\hline RMSE & 5.49 & N/A & 2.97 & N/A \\
\hline Mean & 9.64 & 11.67 & 6.66 & 6.42 \\
\hline
\end{tabular}

\section{Summary}

The sensitivity analysis compared the 2006 sagebrush distributions with various iterations of re-estimates in Wyoming. The comparisons ascertain the most optimal and practical way to further develop training data and satellite imagery for estimating extents and distribution of sagebrush ecosystem components over a large area. Results have the potential to provide recommendations for future large-area attempts to quantify rangeland ecosystems by using remote-sensing information. Several conclusions are listed below.

Number of high-resolution images for Landsat estimation.-The accuracy of sagebrush component estimates did not demonstrate significant differences when different numbers of QuickBird scenes were used as training data within the extent of a Landsat scene. One QuickBird scene could be used to provide percent cover estimates for sagebrush ecosystem components in the extent of a Landsat scene without losing significant accuracy. However, this is dependent upon the quality of training data derived from the QuickBird imagery being reasonably accurate and representing the range of expected habitats in the Landsat footprint.

Training data sensitivity.- This test explored the sensitivities of sagebrush component accuracies based on the total number of field plots used in the prediction. Results indicated that approximately 40 field samples provide the minimum training samples needed to achieve a stable and relatively high accuracy prediction on high-resolution imagery. For example, the RMSE value for bare-ground could be reduced by 169 percent at the 10 field sample level and to 111 percent at the 40 field sample level based on the estimates created using 50 field samples. The $\mathrm{r}^{2}$ value increased from 56 percent with 10 field samples to 87 percent with 40 field samples. The shrub estimate also has a similar pattern.

Estimation across multiple Landsat scenes.-The prediction accuracy of sagebrush components within a single ecoregion suggests that reasonable predictions can be extrapolated from one Landsat scene to an adjacent scene. Adequate training data can be generated from a single Landsat scene and successfully extrapolated for creating distributions of components on up to four adjacent Landsat scene paths/ rows; however, when scene mosaics expand beyond the four adjacent scenes, accuracy will drop, but not significantly. The herbaceous estimate had the lowest accuracy from using more than four Landsat scene mosaics.

Multiple Landsat scene estimation across ecological zones.-The test results suggest that most estimates of sagebrush components across ecoregions maintain relatively high accuracies despite the additional extrapolation. The bareground estimate had the largest $\mathrm{r}^{2}$ and lowest RMSE values when compared to other components, whereas the herbaceous estimate had the lowest accuracy and smallest $\mathrm{r}^{2}$ values.

Overall, the ET-2 tests have better modeling performance than the ET-1 tests do; however, the model estimates using cross ecological zone Landsat scene mosaics could not achieve better accuracies than the four Landsat scene mosaics did in the same ecological zone. The cross ecological zone test result suggests that training data extrapolation should be contained within only similar ecoregions. 


\section{References Cited}

Homer, C.G., Aldridge, C.L., Meyer, D.K., Coan, M.J., and Bowen, Z.H., 2009, Multiscale sagebrush rangeland habitat modeling in southwest Wyoming: U.S. Geological Survey Open-File Report 2009-1027, 14 p.

Homer, C., Aldridge, C., Meyer, D., and Schell, S., 2012, Implementing a multi-scale remote sensing sagebrush habitat monitoring framework: International Journal of Applied Earth Observation and Geoinformation, v. 14, p. 233-244.

Ramsey, R.D., Wright, D.L. Jr., and McGinty, C., 2004, Evaluating the use of Landsat 30m Enhanced Thematic Mapper to monitor vegetation cover in shrub-steppe environments: Geocarto International, v. 19, p. 39-47.

Publishing support provided by:

Rolla Publishing Service Center

For more information concerning this publication, contact:

U.S. Geological Survey Earth Resources Observation

and Science (EROS) Center

47914 252nd Street

Sioux Falls, South Dakota 57198

(605) 594-6151

Or visit the EROS Center Web site at:

http://eros.usgs.gov/
Seefeldt, S.S., and Booth, D.T., 2004, Measuring plant cover in sagebrush steppe rangelands: a comparison of methods: Environmental Management, v. 37, p. 703-711.

Stow, D., Hamada, Y., Coulter, L., and Anguelova, Z., 2008, Monitoring shrubland habitat changes through object-based change identification with airborne multispectral imagery: Remote Sensing of Environment, v. 112, p. 1,051-1,061.

Underwood, E.C., Ustin, S.L., and Ramirez, C.M., 2007, A comparison of spatial and spectral image resolution for mapping invasive plants in coastal California: Environmental Management, v. 39, p. 63-83.

Xian, G., Homer, C., and Aldridge, C., 2012, Assessing long-term variations in sagebrush habitat-characterization of spatial extents and distribution patterns using multi-temporal satellite remote-sensing data; International Journal of Remote Sensing, v. 33, p. 2,034-2,058. 



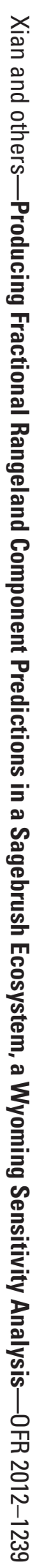

